\title{
EFEITOS DE SENTIDO NA CRÔNICA ESCRITA POR UM ALUNO DO ENSINO FUNDAMENTAL
}

\section{EFFETS DE SENS EN CHRONIQUE ÉCRIT PAR UN ÉTUDIANT FONDAMENTAL EN ÉDUCATION}

\author{
Genilma Dantas Andrade ${ }^{5}$ \\ Maria Leônia Garcia Costa Carvalho ${ }^{6}$
}

\begin{abstract}
RESUMO: Este artigo teve como objetivo verificar os efeitos de sentido decorrentes das marcas de oralidade, em uma crônica produzida por aluno do Ensino Fundamental, da $9^{a}$ série, de uma escola pública de Aracaju e analisar se e como essas marcas podem favorecer a produção do texto escrito. Tal escolha se deveu ao fato de tratar-se de um gênero narrativo mais acessível ao aluno, uma vez que a crônica relata fatos da atualidade e traz aspectos do seu contexto físico e social, aproximando-o mais do cotidiano. Os procedimentos metodológicos utilizados foram: levantamento do material bibliográfico, indispensávelao embasamento teórico, seleção do texto e análise do corpus. O trabalho com o gênero crônica em sala de aula nos levou a concluir que a intersecção da oralidade e escrita em produções textuais, favorece ao desenvolvimento de estratégias imteressantes para a formação de um estilo próprio.
\end{abstract}

PALAVRAS-CHAVE: Aluno. Crônica. Marcas da oralidade.

ABSTRACT: Cet article avait pour objectif de vérifier les effets de sens résultant des marques d'oralité dans une chronique produite par un élève de primaire de $9 \mathrm{e}$ année d'une école publique à Aracaju et d'analyser si et comment ces marques peuvent favoriser la production de texte écrit. . Ce choix est dû au fait qu'il s'agit d'un genre narratif plus accessible à l'élève, puisque la chronique rend compte de l'actualité et rapproche des aspects de leur contexte physique et social de la vie quotidienne. Les procédures méthodologiques utilisées étaient les suivantes: étude du matériel bibliographique, indispensable à la base théorique, sélection du texte et analyse du corpus. Le travail sur le genre chronique en classe nous a amenés à conclure que l'intersection de l'oralité et de l'écriture dans des productions textuelles favorise le développement de stratégies immatérielles pour la formation d'un style propre.

KEYWORDS: Étudiants. Chronique. Les marques de l'oralité.

\section{Introdução}

Este artigo se propôs a averiguar os efeitos de sentido, decorrentes das marcas de oralidade, presentes numa crônica produzida por um estudante do Ensino Fundamental da escola pública Augusto Franco, situada no bairro Santos Dummont, em Aracaju/Se. Tivemos como propósito verificar se e como essas marcas orais favorecem ou não o desenvolvimento produtivo e significativo da escrita.

Como docentes desse nível de ensino, temos a oportunidade de lidar com textos de alunos e observar, neles, inúmeros sinais da língua oral, pelo fato de ainda se encontram em fase de aprendizagem da língua escrita, a todo o momento observam-se interferências da fala na escrita, o que é bastante comum quando ainda não se tem o domínio desta modalidade. Isso se reflete não apenas em questões ortográficas e morfossintáticas, mas na escolha lexical, na organização do texto como um todo e, muitas vezes, no seu sentido.

Dessa forma, trabalhamos, durante as aulas, com o gênero crônica, porque exemplifica um tipo de texto literário que apresenta grande relação com a oralidade, além de surgir de fatos corriqueiros, muito mais ligados à fala e à interação. Também por ser

\footnotetext{
5 Mestra do PPGL da Universidade Federal de Sergipe. E-mail: genilmaandrade2014@gmail.com.

${ }^{6}$ Doutora do DLEV-LETRAS e do PPGL da Universidade Federal de Sergipe. E-mail: marialeoniagarcia@yahoo.com.br.
} 
um tipo de texto literário adepto ao acolhimento de expressões, ditados e provérbios, favorecendo, conforme preconiza Preti (2009), o efeito de coloquialidade emocional argumentativa, ou seja, argumentos pautados na capacidade de fazer inferências sobre estados emocionais.

Daí o elegermos como texto escrito privilegiado para entender como se realiza nele a interseção entre a oralidade e a escrita. A escolha da crônica se deveu, também, ao fato de tratar-se de um gênero narrativo mais acessível ao aluno, uma vez que relata aspectos do seu contexto físico e social e aproxima-o mais do seu cotidiano, por abordar temas da atualidade. $\mathrm{Na}$ crônica, fala-se de tudo, de política a sentimentos pessoais, alçando seja quem for ao papel de autor. Por isso, é considerado um texto dos mais agradáveis de ler e, em consequência, uma estratégia eficaz para inserir o estudante no universo da escrita a partir de temas do seu dia a dia, aproximando-o, assim, das práticas de leitura e escrita. As crônicas, inclusive, por suas características, tornam-se um gênero propício ao uso de formas populares, citações da fala, emprego de estrangeirismos, frases de efeito, infrações à norma culta, transcrevendo uma estrutura própria da linguagem oral.

\title{
2 O gênero crônica
}

Entre o final do século XIX e as duas primeiras décadas do século XX, os textos literários foram publicados em jornais. Essa atividade literária passou a ser um dos pilares do desenvolvimento da leitura na sociedade da época, pois favorecia uma circulação mais rápida e mais barata das obras literárias, o que marcou significativamente esse período. É nesse panorama cultural que surge a crônica, a qual, com o passar do tempo, vai se metamorfoseando e ganhando contornos próprios.

A crônica, oriunda dos folhetins, atende ao tripé autor/obra/leitor como defende Cândido (1992):

\begin{abstract}
Antes de ser crônica propriamente dita foi "folhetim", ou seja, um artigo de rodapé sobre as questões do dia - políticas, sociais, artísticas e literárias. Assim eram os da seç̧ão "Ao Correr da Pena", título significativo à cuja sombra José de Alencar escrevia semanalmente para o Correio Mercantil, de 1854 a 1855. Aos poucos o folhetim foi encurtando e ganhando certa gratuidade, certo ar de quem está escrevendo à toa, sem dar muita importância. Depois, entrou francamente pelo tom ligeiro e encolheu de tamanho, até chegar ao que é hoje (CÂNDIDO, 1992, p.15).
\end{abstract}

A afirmativa de Cândido constrói um panorama do contexto literário em questão. A crônica já nasceu tendo admiradores, por ter um sentido claro e, para Melo (1985), somente no Brasil, a crônica tem "a feição de relato poético do real, situado na fronteira entre a informação de atualidade e a narração literária” (MELO, 1985, p. 111).

Assim, o desenvolvimento desse gênero tornou-se uma inovação própria do jornalismo brasileiro e como gênero autônomo, passa a ser impulsionado simultaneamente à evolução da imprensa no Brasil como observa Coutinho, (2003):

Mas a crônica vem a incorporar-se aos hábitos da nossa imprensa quando se deu o desenvolvimento da imprensa, com a sua modernização, quando se adotam as ilustrações a pena e os clichês fotográficos, quando se aumenta o número das edições. Dispondo de maior espaço, o jornal se enriquece de atrativos e com o noticiário, o grave artigo de fundo e a seções ordinárias, transforma a crônica em matéria cotidiana, como recreio do espírito, amável e brilhante cintilação da inteligência (COUTINHO, [1986] 2003, p. 559).

A crônica revela uma intimidade com o cotidiano do brasileiro, fazendo parte do universo intelectual do país. Inscrita nos mais variados meios de comunicação, ela traz um 
repertório textual e até, como afirma Cândido (1992), sob vários aspectos, é um gênero brasileiro, pela naturalidade com que se aclimatou aqui e a originalidade com que aqui se desenvolveu" (CÂNDIDO, 1992, p. 6-7). Nela, permanece a ideia de registrar o ocorrido em um intervalo de tempo, de servir de memória ao que já passou, e tal característica marca os textos produzidos ao longo da história. Nesse sentido, a crônica é um gênero privilegiado, pois nos permite compreender a relação entre a história da sociedade e a história da linguagem. Assim, desde a mitologia grega se fala do sentido de tempo em relação à crônica.

\subsection{Tipos de crônicas}

Para Cândido (1992), as crônicas podem ser didaticamente classificadas em narrativas, descritivas, narrativo-descritivas, líricas, metalinguísticas, reflexivas e críticas. Apesar dessa classificação, as crônicas são geralmente híbridas (mescla de modalidades). Diante disso, citaremos a seguir a definição de cada tipo de crônica, ainda na perspectiva do autor referido acima (CÂNDIDO, 1992, p. 18-22).

a) Crônica descritiva: predomina a caracterização de elementos no espaço. Utiliza-se dos cinco sentidos, adjetivação abundante e linguagem metafórica.

b) Crônica narrativa: predomina uma história envolvendo personagens e ações (enredo) que transcorrem no tempo.

c) Crônica narrativo-descritiva: predomina a narração, e os trechos descritivos caracterizam o cenário e os personagens.

d) Crônica lírica: apresenta linguagem poética e metafórica, predominando a emoção e os sentimentos.

e) Crônica metalinguística: é a crônica que fala sobre o próprio ato de escrever, o fazer literário, o ato de criação.

f) Crônica reflexiva: o autor tece reflexões filosóficas, isto é, analisa subjetivamente os mais variados assuntos e situações.

g) Crônica argumentativa: tipo de gênero textual que reúne características de crônica e de texto argumentativo; posicionamento do cronista sobre o assunto em questão; exposição de argumentos que fundamentam o ponto de vista do autor; tratamento subjetivo do tema, deixando perpassar a sensibilidade e as emoções do cronista; linguagem criativa e figurada, geralmente, de acordo com o padrão culto informal da língua.

Embora exista uma tipificação das crônicas, isto não quer dizer que não exista uma imbricação de vários tipos ainda que um deles predomine. Explicando melhor, em uma crônica narrativa, sem dúvida alguma, predomina a narração, mas isto não impede que haja caracterização dos personagens e/ou cenário, por meio de adjetivação, de uso de expressões ou outros recursos de linguagem que enriqueçam a narrativa.

Da mesma forma, pode acontecer a outros tipos de crônica: a reflexiva, a lírica, a argumentativa etc. Haverá sempre outros elementos descritivos, narrativos, ou de outras espécies de crônica que se somarão ao tipo predominante para torná-la mais interessante, mais rica e expressiva. A linguagem da crônica, além dos inúmeros recursos da língua que estão à disposição do artista, conta com a criatividade do escritor e enriquece-se através de suas experiências e vivências pessoais. 


\section{Discurso e efeitos de sentido}

Como nosso propósito é evidenciar os efeitos de sentido das marcas da oralidade na crônica produzida por um aluno do Ensino Fundamental, cabe-nos aqui tentar explicar o que seria "efeito de sentido". Para isto, recorremos à Análise do Discurso de origem francesa, que considera que o "sentido" é um "efeito de sentido" entre os locutores, é o lugar de contato entre língua e ideologia (ORLANDI, 1992, p.20).

Conforme Possenti (2002, p. 169), essa definição seria melhor compreendida "em uma concepção de linguagem que considerasse de alguma forma a enunciação", uma vez que ela não é definida claramente na Análise do Discurso.

Em seu livro (1969, p.82), Pêcheux faz menção à teoria da comunicação formulada por Jakobson que faz referência à mensagem 'como transmissão de informação', descartando-a ao preferir o termo discurso, que implica não necessariamente uma transmissão de informação, entre A e B, mas, de modo geral, de um "efeito de sentidos" entre os pontos A e B.

Para Possenti (2002, p. 170), o que Pêcheux propõe é que a noção de efeito de sentido seja concebida como uma espécie de conceito guarda-chuva, para ocupar o lugar da mensagem (entendida em geral como transmissão de informação, como bem observa Ducrot [1972], (2010) a propósito das teorias da comunicação) rompendo assim com a teoria que propõe aquele conceito. Para o autor, Pêcheux, ao referir-se a sentido, não tenta concebê-lo como uma mensagem codificada num texto, numa língua, como um conteúdo embutido num código, trata-se de informação ou de outra coisa, o sentido é sempre um efeito, trata-se do efeito de uma atividade: a enunciação. Do ponto de vista da $\mathrm{AD}$, “o sentido não está associado simplesmente nem às palavras, nem aos enunciados, mas depende, de alguma forma, exatamente, da enunciação dos enunciados, o que, por sua vez, depende de condições específicas" (O discurso é, por natureza, histórico, ideológico).

A noção de efeito de sentido precisa, ainda, ser articulada a outras colunas da $\mathrm{AD}$, como ao fato de Pêcheux (1990) considerar que o discurso não tem início, pois o sentido delas remete a ocorrências anteriores, a outros discursos. Ou ainda: qualquer enunciação supõe uma posição e é a partir dessa posição que os enunciados (palavras) recebem seu sentido. Qualquer uma das posições implica uma memória discursiva, de modo que as formulações não nascem de um sujeito que apenas segue as regras de uma língua, mas do interdiscurso, vale dizer, as formulações estão sempre relacionadas a outras formulações.

Ora, no caso dos efeitos de sentido que palavras ou expressões da oralidade produzem nas crônicas escritas, consideramos que as palavras utilizadas na fala quotidiana já trazem uma conotação decorrente da atividade de enunciação, remetendo a discursos anteriores já enunciados, já ditos. Contudo, nem sempre o efeito de sentido está ligado a um interdiscurso, pode estar relacionado a um modo de dizer, a um artifício da língua oral que gera sentido, por exemplo: o uso do diminutivo pode expressar carinho (pequenina, amorzinho), piedade (coitadinha), entre outros efeitos. O uso do pronome oblíquo iniciando frase, abranda o imperativo, suavizando a expressão: Me dê uma esmola! Me dê um pouco d'água! O uso de certos sufixos ou de certas locuções adjetivas dão ideia de desprezo: Ele é um velhaco! É uma mulher da vida! E assim por diante.

Por outro lado, ainda há, também, a posição do enunciador que se manifesta em sua fala e que ganha mais força de expressão em decorrência de fatores diversos, como o tom da voz, a altura, o timbre e, até mesmo, certos termos do quotidiano já conhecidos e que expressam sentidos os mais variados. 


\section{Metodologia e análise}

Em nosso estudo, utilizamos o método qualitativo na investigação e interpretação de enunciados orais e escritos, procurando identificar efeitos de sentido provocados pelas marcas da oralidade, em texto de aluno do $9^{\circ}$ ano do ensino fundamental.

A crônica do aluno é analisada a partir das marcas da oralidade, como espacialização, paráfrase, repetição, dentre outras, relacionando-as com as características da crônica em diferentes perspectivas. Observamos, também, o enquadramento dos marcadores conversacionais, uma vez que, por meio deles, são produzidos efeitos de sentido.

\subsection{Análise e interpretação do corpus}

Neste item nos voltaremos à análise do nosso corpus constituído de textos produzidos em aula, por aluno da $9^{\circ}$ ano do Ensino Fundamental.

\section{A crônica}

Estou aqui Pensando em esclareser o que quero dessa vida, mas muitas pessoas cismam de me mandar.

Talvez seja o fato de enterterimento que teria, mas no maximo um toque no objetivo que mim aparecer agora. Porque infelizmente de humildade dotado. Para mim alegra positividade no dia-a-dia. Resolveu mim empatar com minhas maravilhosas leituras, cheias de alegria, flores, bichinhos e a musica em que mim tras em fatos de mensagens. em ações, afirmações, correntes de amizades, dali apareceu a mais linda dama. Pessoas mais proximas de mim, que ótimo dia a conhecir com paisagens no fundo do livro.

\section{Análise do texto}

\section{Posição do sujeito e efeitos de sentido}

Tomemos o seguinte fragmento:

"[...] mas muitas pessoas cismam de me mandar".

Podemos dizer que os enunciados abaixo podem parafrasear aspectos do fragmento acima:

(1) O termo cisma (dissidência de sentido) apresenta no senso comum o sentido de teimar, implicar - paráfrase A: As pessoas teimam em me mandar.

(2) Cismam de conduzir - cismam no dicionário tem o sentido de meditar, cogitar paráfrase de B: As pessoas cogitam em me conduzir.

O que a diferença de corpo das letras indica? Esta diferença nos dá uma pista de que devemos interpretar a partir de uma posição teórica. Daí temos: como interpretar o efeito de unidade de níveis diferentes? Guimarães (2005) considera o interdiscurso como memória do dizer, como o dizível, podemos assumir a posição de que os sentidos em um acontecimento são efeitos da presença do interdiscurso. Ou melhor, são efeitos do cruzamento de discursos diferentes no acontecimento (GUIMARÃES, 2005, p. 67). No caso do texto acima, tem-se, de um lado, o discurso do senso comum que formulamos pela paráfrase (1), e a posição "moral" de quem tem "autoridade", que formulamos pela paráfrase (2). Segundo Guimarães (2005), temos então, dois recortes de interdiscurso no texto: o linguístico-lexicológico, que se legitima na ciência e o "moral" que se legitima no valor da vida para o senso comum. 


\section{Efeitos de sentido da oralidade: temporais, espaciais e actoriais ${ }^{7}$.}

Para Preti (2009) os efeitos de sentido como: proximidade, descontração/ informalidade, falta de acabamento/de completude, caráter passageiro e simetria/ reciprocidade, podem ser determinados positiva ou negativamente, (PRETI, 2009, p. 43). Assim, por exemplo, o efeito temporal pode ser considerado como passageiro, efêmero, que tem efeito negativo. Dessa forma, o mesmo atributo de caráter passageiro da fala pode caracterizá-la como mais "leve", "sincera" e "inovadora", considerando positivo, pois com ela tudo pode ser dito. Como nos trechos apresentados a seguir: me mandar".

"Estou aqui pensando em esclareser o que quero dessa vida, mas muitas pessoas cismam de

"Talvez seja o fato de Enterterimento que teria, mas no maximo um toque no objetivo que mim aparecer agora".

Observam-se, também, além de certa incompletude das frases, usos próprios da oralidade, como a troca dos pronomes oblíquos me por mim ou vice-versa, problemas de grafia, sobretudo visíveis na troca de letras e na ausência de sinais de pontuação e de acentuação:

"Porque infelizmente de humildade dotado Para mim alegra positividade no dia-a-dia [...]".

"Resolveu mim empatar com minhas maravilhosas leituras, cheias de alegria, flores, bichinhos e a musica em que mim tras em fatos de mensagens".

"Pessoas mais proximas de mim que ótimo dia [...]".

No texto em análise, foram encontrados procedimentos linguístico-discursivos que por um lado, mostram ainda desconhecimento da norma padrão, por outro, contribuem para originar certos efeitos de sentido decorrentes das marcas de oralidade. São eles:

- Recursos temporais e espaciais de emprego do aqui e agora; que produzem o efeito de aproximação temporal e espacial da enunciação, e reforçam, portanto, os efeitos da oralidade.

- Uso de vocábulos considerados próprios da fala, tais como: utilização frequente do pronome oblíquo mim, truncamentos de palavras e erros de grafia em que se alternam variantes mais cultas com variantes mais populares.

\section{O sentido como intenção do locutor}

Uma análise conversacional constrói a simulação de um raciocínio do ouvinte a partir do enunciado dito pelo locutor. A exemplo do enunciado:

“(1) Estou aqui Pensando em esclareser o que quero dessa vida, mas muitas pessoas cismam de me mandar".

O que alguém está dizendo ao falar (1)? A resposta a essa pergunta considera que o sentido, a intenção do que o locutor diz, deve ser interpretado levando-se em conta o sentido literal de (1), ou seja, esse enunciado significa, independentemente de sua situação de uso,

\footnotetext{
${ }^{7}$ Preti (2009) afirma que o termo ator é empregado pela semiótica para tratar dos sujeitos que assumem papéis na organização narrativa do discurso, que são investidos pela categoria linguística de pessoa e preenchidos por temas e/ou figuras do discurso.
} 
embora seja necessário, também, levar em conta a situação em que é dito. Para Guimarães (2005), trata-se de um sujeito consciente de suas intenções, capaz de comunicá-las, ou seja, a intenção que institui o sentido é tal que se dá a conhecer por si mesma (GUIMARÃES, 2005, p. 31). Portanto, o modo como a situação opera está relacionado a um conjunto de princípios que regem a conversação.

\section{Considerações finais}

Como vimos, no decorrer desta pesquisa, foi possível constatar a importância do trabalho com o gênero crônicas, tanto pelo material utilizado - a crônica produzida por aluno do Ensino Fundamental - que mostra por meio de uma linguagem simples, seu posicionamento perante vários assuntos que envolvem a própria vida e a sociedade, quanto pela relevância dada ao gênero, por se tratar de um instrumento adequado para $o$ desenvolvimento do trabalho com a escrita.

Observamos que a crônica que constituiu o corpus dessa pesquisa, embora apresente problemas diversos de ordem ortográfica, morfossintática e textual, decorrentes, em grande parte, do processo de ensino-aprendizagem, demonstra que seu produtor consegue, mesmo sem ter o domínio da língua padrão, manifestar suas ideias, as percepções que tem do mundo a sua volta, do seu cotidiano, das pessoas com quem convive e dos fatos que se sucedem, havendo em seu texto coerência, ainda que não saiba organizar de forma apropriada as estruturas textuais, nem utilizar os mecanismos de coesão, de referência, adequados. Daí porque se ressaltam os usos da língua oral, muitas vezes em decorrência do costume de empregá-los em seu dia a dia.

Mesmo assim, percebemos que o uso de formas orais costumeiras nem sempre depreciam seus textos, ao contrário, muitas vezes até os enriquecem. Entendemos, também, que é possível reafirmar, por meio do estudo do gênero crônica, que a fala e a escrita não se realizam, pois, como menciona Marcuschi (2001), o que determina a forma de organização textual é o propósito do fato e a condição dos interlocutores. Assim, para enriquecer e ampliar o universo do aluno é de suma importância trabalhar com texto oral e escrito. Referir-se à crônica, analisar as marcas da oralidade presentes nela, incentivar o aluno a praticar a leitura atentando para sua estrutura, suas características, bem como sua função, é levar o aluno a trabalhar de modo mais eficaz as práticas sociais da leitura e da escrita, além de fazê-lo construir seu próprio conceito de crônica, pois atitudes estas nem sempre acontecem durante as aulas corriqueiras.

Um fato positivo que foi observado no desenvolvimento da crônica produzida pelo aluno, foi a linguagem figurada empregada por ele nesse gênero textual, que alavanca elementos capazes de emocionar e envolver o leitor para que reflita sobre aspectos do cotidiano apresentados pelo texto escrito, motivando assim, grande parte dos alunos à leitura e à escrita. Assim, o estudo da língua portuguesa será mais agradável e atrativo, tornando os aprendizes capazes de identificar traços linguístico-discursivos que constituem não apenas este gênero, mas diversos outros que forem trabalhados, fazendo, dessa maneira, a leitura e o estudo da língua mais significativos

É, principalmente, no ensino de língua portuguesa que se deve valorizar todas as possibilidades de produção textual, destacando os efeitos de sentido e as estruturas linguísticas usadas, como também considerando as marcas da oralidade não como desvios da norma culta, tão questionáveis como certos ou errados, mas como geradoras de sentido.

A partir da análise do corpus deste trabalho, produzido por estudante do $9^{\circ}$ ano, sujeito de nossa pesquisa, objetivamos refletir sobre a importância de um letramento pautado na integração da linguagem verbal e não verbal, a fim de desenvolver nos alunos habilidades de 
compreensão e uso de múltiplos recursos de linguagem, em diferentes gêneros orais e escritos. A percepção dos efeitos de sentido que as marcas da oralidade engendram é basilar para que eles desenvolvam não apenas bons textos, mas que também aprimorem seu estilo e entendam a língua oral não como incorreta ou inferior à escrita, mas como complemento do seu desempenho linguístico.

\section{Referências}

CÂNDIDO, A. A crônica: o gênero, sua fixação e suas transformações no Brasil. Rio de Janeiro: Ed. da Unicamp: Fundação Casa de Rui Barbosa. 1992.

COUTINHO, A. A literatura no Brasil. Vol. 6, Parte III - Relações e Perspectivas.

Codireção Eduardo de Faria Coutinho. 6. ed. São Paulo: Global, [1997], 2003.

DUCROT, O. Dizer e não dizer. Princípios de Linguística Semântica. São Paulo: Cultrix, [1972] 2010.

GUIMARÃES, E. Os limites do sentido: um estudo histórico e enunciativo da linguagem.

Campinas, SP: pontes, $3^{\mathrm{a}}$ edição, 2005.

MARCUSCHI, L. A. Da fala para a escrita. Atividade de retextualização. 2. ed. São Paulo: Cortez, [1997], 2001.

MELO, J. M. de. A crônica. In: CASTRO, G. de; GALENO, A. (Orgs.). Jornalismo e Literatura - A sedução da palavra. São Paulo: Escrituras, [1985], 2002.

ORLANDI, E. P. As formas do silêncio. Campinas, Editora da Unicamp. 1992.

POSSENTI, S. Os limites do discurso: ensaios sobre discurso e sujeito. São Paulo: Parábola Editorial, 2002.

PRETI, D. (Org.). Oralidade em textos escritos. São Paulo: Humanitas, 2009.

Submetido em 28/09/18

Aceito em 20/12/2018 